\title{
An Investigation of Teachers' Needs for Successful Implementation of Teaching and Learning Policies
}

\author{
Tebogo Mogashoa \\ University of South Africa \\ Department of Curriculum and Instructional Studies \\ PO Box 392, 0003 Unisa, South Africa \\ Email: mogasti@unisa.ac.za
}

\section{Doi:10.5901/mjss.2014.v5n9p366}

\begin{abstract}
The aim of the research was to investigate teachers' needs for successful implementation of teaching and learning policies in primary schools. This study was underpinned by constructivism and sociocultural theories. Qualitative research assisted the researcher to investigate teachers' needs for successful implementation of teaching and learning policies in primary schools. Data analysis took place throughout data collection process. It has been established in this study that schools in urban areas were better supplied with teaching and learning support materials than the schools on the farms. The findings revealed that workload and resources were major challenges to most teachers. Teachers should improvise resources by planning and executing activities together. For planning of activities to be successful, it is important to make sure that the learning and teaching support materials are available in the planning process.
\end{abstract}

Keywords: Democracy, constructivism, sociocultural, empirical, impressions and expressions.

\section{Introduction and Context of the Study}

Before 1994 the education system in South Africa contradicted world trends by deliberately choosing to serve the education needs of only a section of the South African population. The birth of democracy in 1994 led to the establishment of a new dispensation and a concomitant need for the democratisation of the education system. The apartheid education system disadvantaged the majority of South Africans especially the black communities. A new democracy demanded change in many spheres of life in South Africa and particular, in education.

Outcomes-based education emphasises that learners should master learning outcomes and be able to work cooperatively. Spady (1994:19) describes "transformational outcomes" as learning "that require the highest degree of ownership, integration, synthesis, and functional application of prior learning because they (learners) must respond to the complexity of real-life performances." The emphasis in outcomes-based education is involving learners in learning activities that would lead them to achieve particular learning outcomes.

According to Samuels (2009:1), research is designed to solve a particular existing problem so that there is a much larger audience eager to support research that is likely to be profitable or solve problems of immediate concern. The education policies on teaching and learning in South African schools have been reviewed and streamlined, that is, from Curriculum 2005 to the Revised National Curriculum Statement (RNCS) and from the National Curriculum Statement (NCS) to the Curriculum and Assessment Policy Statement (CAPS). The CAPS was implemented in 2011 in the Foundation Phase, and for all the other phases by the end of 2012. It is imperative to look at what teachers need in order to implement teaching and learning policies successfully.

\section{Theoretical Frameworks}

This study was underpinned by constructivism and sociocultural theories. According to Piaget (1971:7), learning is the results of individual construction of knowledge, whereby learners use their prior knowledge and experience to integrate it with the new information, thus constructing their new knowledge and understanding. A learner belongs to social community, which is, the teacher, parents and peers. Therefore higher mental process develops through social interaction. The teacher's role is to build an environment that is stimulating and conducive to the process of constructing meaning and knowledge.

Sociocultural theory dictates that learning is active and constructed. In a learning environment, learning theories 
are vital parts of the teaching and learning situation because the teaching strategies emanate from learning theories. According to Ornstein and Hunkins (2009:31), philosophy is central to curriculum. The philosophy of a particular school and its officials influence the goals, content, and organization of its curriculum. Philosophy provides curriculum implementers with a framework or frameworks for organizing schools and classrooms. Philosophy clarifies educational goals, suitable content, teaching and learning process, and the experiences and activities that schools emphasize. The main research question is as follows:

What are teachers' needs for successful implementation of teaching and learning policies in primary schools?

\section{Research Design and Methods}

The purpose of the research design is to specify a plan for generating empirical evidence that will be used to answer the research questions. It summarizes the procedures for conducting research including who, how and what methods of data collection and analyses to be used (McMillan and Schumacher 2010:11). The interactive qualitative research design was used to gather data using ethnographic method and the researcher was in the prolonged fieldwork employing participants' observations, semi-structured interviews and literature review. There were discussions between the teachers and the researcher in order to interpret the meaning and the significance of their teaching and learning.

Population is a group of elements which conform to specific criteria from which generalization is made (MacMillan and Schumacher 2010:17). Schools are located in Gauteng North District of the Gauteng Department of Basic Education. The researcher focused on 20 teachers in the intermediate phase in five primary schools. For the sake of anonymity, the teachers are named $A, B, C, D$, etc.

\section{Data Analysis and Interpretation}

Data analysis took place throughout data collection process. It was constantly reflected on impressions, relationships and connections while collecting data. The research for similarities, differences, categories and ideas formed part of the continuous process (Henning et al, 2007:127). The research problem served as a guide in conducting the analysis. The collected data was broken into small units of meaning.

\section{Research Findings and Discussions}

5.1 "What role do you think School Management Team (SMT) play in supporting and guiding you in implementing teaching and learning policies?"

In answering the question above, 12 teachers in schools A, B and C indicated that their SMTs are very supportive but eight teachers in schools D and E indicated that they did not have an SMT in their school. A few of the verbatim responses are indicated below:

Teacher K, "The SMT gives us money to buy learning and teaching support materials. We work as a team and we have about three staff meetings each term where we discuss challenges we might have".

Teacher F, "What? SMT? We don't have such a thing. Actually, we don't even have a principal. We just assist one another informally".

The above responses were followed by another question to determine how effective the SMT's in their respective schools are.

\section{2 "How effective is the School Management Team (SMT) in leading this institution?"}

The responses from 12 teachers in schools $A, B$ and $C$ reflected that their SMTs are effective while in schools $D$ and $E$, SMTs did not exist. This was vividly depicted by some of the teachers in the following statements:

Teacher N, "Our SMT gives us the support we need".

Teacher H, "Members of our SMT guide us in implementing the various policies on teaching and learning".

Teacher $P$, "There is no SMT in our school".

In order to determine the effectiveness of team work, the following question was asked: 


\section{3 "What opportunities are created for team work in the Intermediate Phase?"}

The responses from 12 teachers in schools A, B and C indicated that SMTs created opportunities for them to learn more about teaching and learning policies, while in schools $D$ and $E, 8$ participants indicated that SMTs did not exist. A few of the verbatim responses are indicated below:

Teacher $C$, "We have morning briefs and staff meetings where we assist one another. The HODs organise meetings and we discuss challenges that we have in our phase and how to solve them".

Teacher R, "Our principal and HODs always encourage us to help one another and to work as a team. We have meetings and workshops in order to assist one another".

Teacher B, "There is no SMT and we don't work as a team".

5.4 "What kind of guidance and assistance did you receive from the School Management Team (SMT) in respect of assessment procedures and practices?"

The responses from 12 teachers in schools A, B and C indicated that SMTs organised some workshops to empower them. In schools D and E, 8 teachers indicated that SMTs did not exist. This was vividly depicted by the following statements:

Teacher S, "Our SMT guides us on the various assessment procedures. We use assessment policies supplied by the Department of Education".

Teacher G, "Members of our SMT guide us in implementing the various policies on assessment".

Teacher M, "There is no SMT in our school. However, we attend workshops on assessment policies".

To establish teachers' requirements for the successful implementation of teaching and learning policies, the following question was asked:

\section{5 "What are your needs for the successful implementation of the new policies on teaching and learning?"}

Twenty (20) teachers who participated in this study indicated that they would prefer greater stability and continuity in teaching and learning policies issued by the Department of Basic Education.

A few of the verbatim responses are indicated below:

Teacher J, "The Department of Education should not change teaching and learning policies. These policies always change and this causes confusion".

Teacher B, "The Department of Education must not always change policies".

Teacher T, "New teaching and learning policies are confusing us because they always change. The Department of Basic Education should not change these policies".

The next question was asked to determine teachers' challenges in the implementation of the new policies on teaching and learning.

\section{6 "What challenges do you encounter in the implementation of the new policies on teaching and learning?"}

Fifteen (15) teachers who participated in this study complained about the workload while eight teachers complained about the resources. Teacher $L$ said, "Workload. It hinders our progress in teaching. I sometimes spend more time dealing with paper work instead of teaching the learners". Another participant, teacher D said, "I think the resources and time are our major challenges. Sometimes there are no enough periods to deal with all the learning outcomes and assessment standards".

\section{Conclusions and Recommendations}

In this study some teachers indicated that members of SMTs were supportive, while others indicated that they did not have SMTs. The study found that schools in urban areas were better supplied with teaching and learning support materials than the schools on the farms. Teachers could not interpret teaching and learning policies appropriately. Furthermore, this study established that workload and resources were major challenges to most teachers. 
The Department of Basic Education is encouraged to give more financial support to schools in order to provide the basic infrastructure. Schools should be provided with sufficient infrastructure that allows easy access to resources for both teachers and learners. School libraries should be well equipped to offer effective service to teachers and learners. Librarians should be appointed to manage the libraries effectively. Furthermore, current resources should also be reviewed to align with new developments. The Department of Basic Education should ensure that every school has the minimum of resources to function well enough to deliver quality education. Teachers in former disadvantaged schools should liaise with teachers in the former Model $\mathrm{C}$ schools to learn effective use of modern resources. The Department of Basic Education should also make sure that all schools receive resources on time and that they are available to all schools.

Teachers should improvise resources by planning and executing activities together. Improvisation in English language requires creativity and resourcefulness; local resources in the immediate environment should be used to develop instructional teaching-learning materials that can assist in the smooth dissemination and transfer of knowledge from teachers to students (Emeka 2009:3). Improvisation requires that teachers use resources available in the surrounding area (Yara 2010:3). Asokhia (2009:80) suggests the following guidelines on how to improvise for the lower levels: making cut-out alphabets from old calendars and cardboards, using flashcards to depict the new words in a passage for the older learners, using cut out letters or words for matching or organising experience, engaging learners in the art in order to fascinate them as well as orderly and neatly managing the available space in the classroom. There are possibilities of alternatives to teaching and learning aids, for example if teachers need magnets, they can harvest them from broken microwaves and loud speakers. The internet also has many resources for teachers that can significantly increase the content of teachers' teaching toolboxes.

Learning and teaching support materials should be used to contribute to planning of classroom activities. For planning of activities to be successful, it is important to make sure that the learning and teaching support materials are available in the planning process. Teachers should use learning and teaching support materials in team planning. The researcher recommends that teachers should increase time spent on planning lessons using the learning and teaching support materials provided. Consideration should also be given to using learning and teaching support materials that support the learning goals/objectives. Learning and teaching support materials should be used to contribute to the teachers' knowledge of learning outcomes. Learning and teaching support materials should be used to improve learner participation and the achievement of learning outcomes and assessment standards.

It is further recommended that teachers should manage situations where learning and teaching support materials change the intended activities carefully. The Department of Basic Education and the school should ensure that the learning and teaching support materials also cater for the learners who experience barriers to learning. Picture-based learning and teaching support materials can be useful in overcoming language barriers. Teachers should be guided by the best textbooks available in designing their learning programmes.

Developing materials in a multilingual environment requires teachers to carefully consider language issues from a number of different perspectives, for example, learners' age, the language they speak at home or in the community as well as their fluency in the language of learning and teaching. Another issue to consider is the level of language used. Teachers should also consider the language used in the materials as this can have both negative and positive impact on participation of learners in their classroom performance. Teachers should carefully consider how the lesson can be structured to maximise learners' ability to use limited learning and teaching support materials.

\section{References}

Asokhia, M.O. 2009. Improvisation/Teaching Aids: Aid to Effective Teaching of English language. International Education Science. 1 (2): 79-85.

Emeka, C. 2009. Uses of Improvisation and learning resources in school. Ontario. Durham College Press. Heining, G.E. 2007. Constructivist Learning Theory. Manachusetts. Lesley College Press. McMillan, J.H \& Schumacher S. 2010. Research in education, evidence- based inquiry. Seventh edition. Boston: Pearson. Ornstein, AC \&Hunkins. F. 2009. Curriculum- foundations, principles and issues. Boston :Ally \& Bacon. Samuels, P. 2009. The importance of research- Why we do research? London. Sage Publications. Spady, W.G. 1994. Outcomes-based education, critical issues and answers. Virginia: American Association of School Administrators. Yara, P.O. 2010. Teaching/learning Resources and Academic Performance in Mathematics in Secondary Schools in Bondo District of Kenya. Kampala. Kampala International University. 